\title{
Amelioration of the Cooling Load based Chiller Sequencing Control
}

\author{
Sen Huang ${ }^{a}$, Wangda Zuo ${ }^{a, *}$, Michael D. Sohn ${ }^{b}$ \\ ${ }^{a}$ Department of Civil, Architectural and Environmental Engineering, University of Miami, \\ 1251 Memorial Drive, Coral Gables, FL 33146, U.S.A. \\ ${ }^{b}$ Energy Analysis and Environmental Impacts Division, Lawrence Berkeley National Laboratory, \\ One Cyclotron Road, Berkeley, CA 94720, U.S.A.
}

\begin{abstract}
:
Cooling Load based Control (CLC) for the chiller sequencing is a commonly used control strategy for multiple-chiller plants. To improve the energy efficiency of these chiller plants, researchers proposed various CLC optimization approaches, which can be divided into two groups: studies to optimize the load distribution and studies to identify the optimal number of operating chillers. However, both groups have their own deficiencies and do not consider the impact of each other. This paper aims to improve the CLC by proposing three new approaches. The first optimizes the load distribution by adjusting the critical points for the chiller staging, which is easier to be implemented than the existing approaches. In addition, by considering the impact of the load distribution on the cooling tower energy consumption and the pump energy consumption, this approach can achieve a better energy saving. The second optimizes the number of the operating chillers by modulating the critical points and the condenser water set point in order to achieve the minimal energy consumption of the entire chiller plant that may not be guaranteed by existing approaches. The third combines the first two approaches to provide a holistic solution. The proposed three approaches were evaluated via a case study. The results show that the total energy consumption saving for the studied chiller plant is $0.5 \%, 5.3 \%$ and $5.6 \%$ by the three approaches, respectively. An energy saving of $4.9 \%$ to $11.8 \%$ can be achieved for the chillers at the cost of more energy consumption by the cooling towers (increases of $5.8 \%$ to $43.8 \%$ ). The pumps' energy saving varies from $-8.6 \%$ to $2.0 \%$, depending on the approaches.
\end{abstract}

Keywords: Multiple-chiller Plant; Chiller Sequencing Control; Model-based Optimization

* Corresponding author: w.zuo@ miami.edu

(C) 2016. This manuscript version is made available under the Elsevier user license

http://www.elsevier.com/open-access/userlicense/1.0/ 


\section{Introduction}

\subsection{Background}

In the United States, commercial building cooling equipment consumed around 77.4 GWh primary energy in 2010 [1]. Chiller plants are widely used to provide cooling for large buildings, data centers and district cooling systems. As major components of the chiller plants, chillers alone represented about $35 \%$ of the energy consumption by the commercial building cooling [2]. Due to their significant energy consumption, optimal control of the chiller plants is of great interest to the nation. To enhance the operational efficiency of the chiller plants, many researchers have devoted efforts to achieve the optimal control of the plants. As a result, many approaches have been proposed [3-43].

Among various configurations of chiller plants, the multiple-chiller plants are the most widely used. For those plants, it is recommended to operate chillers sequentially rather than simultaneously [44]. To operate chillers in sequence, one uses a chiller sequencing control, usually based on the cooling load, to bring chillers online or offline. Depending on the approach to indicate the cooling load, the chiller sequencing control can be categorized as: the return chilled water temperature based control, the bypass flow based control, the direct power based control, and the Cooling Load based Control (CLC) [45]. Among them, the CLC is considered to be the most promising because other approaches employ the use of indirect indicators of the cooling load (e.g. the return chilled water temperature, the volume flow rate at bypass of secondary loop, and the chiller power), which may not be proportional to the cooling load [21]. The CLC directly calculates the cooling load using the chilled water flow rate and the difference between the chilled water supply temperature and return temperature [9].

In the CLC, one chiller will not be brought online/offline unless the cooling load is larger/smaller than the total available cooling capacity of the operating chillers. The total available cooling capacity of $i$ operating chillers can be referred as a Critical Point $(C P)$ :

$$
C P_{i}=\sum_{j=1}^{i} C C_{a c t, j}
$$

where $C C_{a c t, j}$ is the actual cooling capacity of the $j t h$ chiller. In the real world implementation, the nominal capacity of the chiller, $C C_{n o m, j}$, is conventionally used to represent $C C_{a c t, j}$. Thus, equation (1) can be converted into:

$$
C P_{i}=\eta \sum_{j=1}^{i} C C_{n o m, j},
$$

where $\eta$ is the safety factor (e.g., 90\%) to mitigate the risk of insufficient cooling supply during the chiller start-up period. Besides, a state machine [46] can also be used to facilitate the implementation of the CLC. To avoid a chiller short circling, a waiting time $t_{w a i t}$ and a dead band $C P_{d b}$ are usually employed. For 
instance, Figure 1 shows a conventional CLC for a chiller plant with three identical chillers. The transition between states indicates adding or reducing the number of the operating chillers.

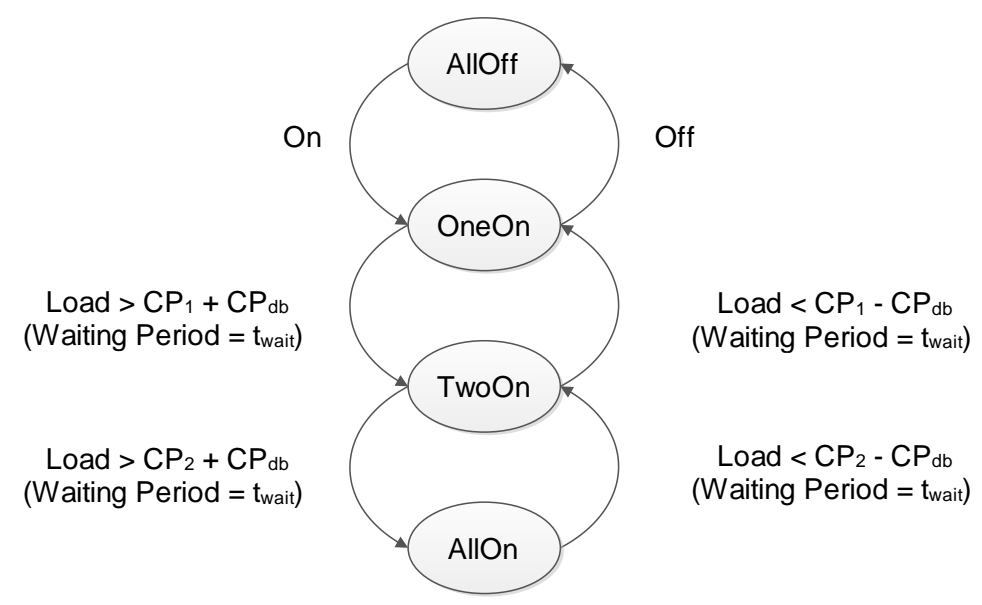

Figure 1 The state machine of a conventional CLC for a chiller plant with three identical chillers

\subsection{CLC Optimization}

Although widely used, the conventional CLC has limitations and can't guarantee the minimal energy consumption by the chiller plants. To improve the energy efficiency of the chiller plants, researchers proposed various CLC optimization approaches [5-7, 9, 20-33, 40-43]. Generally speaking, those approaches can be divided into two groups: studies to optimize the load distribution and studies to identify the optimal number of operating chillers. We will discuss the concept and the limitations of each group as follows.

The first group aims to optimize the load distribution among the chillers. The conventional CLC turns on an additional chiller only when the cooling loading approaches the total nominal cooling capacity of the operating chillers. This means that chillers will work at the highest Partial Load Ratio (PLR). The PLR is the ratio of the cooling load handled by one chiller to its nominal cooling capacity. However, the ASHRAE Handbook [44] points out that a higher chiller PLR does not necessarily mean a higher operational efficiency. The chiller's operational efficiency is usually measured by the coefficient of performance $(C O P)$, which is the ratio of the cooling energy provided by the chiller to its power consumption. Figure 2 shows that the highest COPs may occur at relatively low PLRs for three different chillers. 


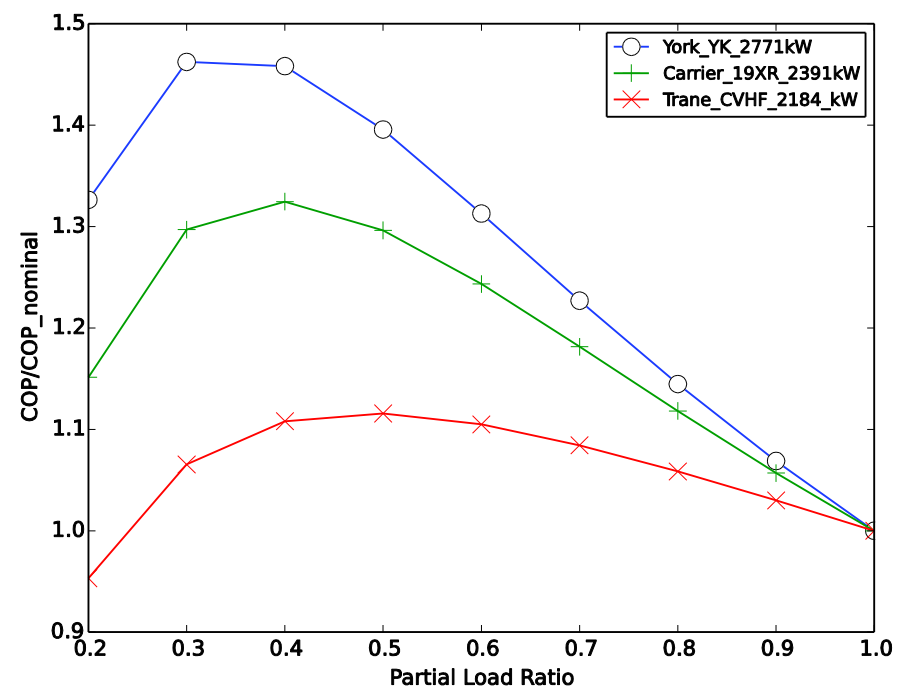

Figure 2 The relationship between PLRs and the relative COPs for three different chillers calculated according to the chiller dataset provided by EnergyPlus [47]

To achieve the optimal load distribution, researchers developed model based optimization approaches to adjust the PLR of each chiller individually according to a given cooling load [5, 7, 22-33]. Some studies aimed to maximize a summation of the operating chillers' $C O P$ as follows [5, 22, 24, 33]:

$$
\begin{aligned}
& J=\max \left(\sum_{i=1}^{M} C O P_{i}\right), \\
& \text { s.t. } \\
& \sum_{i=1}^{M} P L R_{i} C C_{\text {nom }, i}=\dot{Q},
\end{aligned}
$$

where $C O P_{i}$ and $P L R_{i}$ are the $C O P$ and $P L R$ of the $i$ th chiller, respectively. The $M$ is the number of the chillers in the chiller plant and $\dot{Q}$ is the cooling load. They utilized a regressed PLR-COP curve in equation (5) to calculate the $C O P_{i}$ under the $P L R_{i}$ :

$$
C O P_{i}=\sum_{j=0}^{m} a_{j} P L R_{i}{ }^{j},
$$

where $a_{j}$ is the $j$ th constant coefficient and $m$ is the number of the constant coefficients.

Other approaches tried to minimize the sum of the chillers' power as follows [7, 23, 25-32]:

$$
\begin{aligned}
& J=\min \left(\sum_{i=1}^{M} P_{c h, i}\right), \\
& \text { s.t. } \\
& \sum_{i=1}^{M} P L R_{i} C C_{n o m, i}=\dot{Q},
\end{aligned}
$$

where $P_{c h, i}$ is the power of the $i$ th chiller. The regressed Power-PLR curve in equation (8) was employed to calculate $P_{c h, i}$.

$$
P_{c h, i}=\sum_{j=0}^{n} b_{j} P L R_{i}{ }^{j},
$$

where $b_{j}$ is the $j$ th constant coefficient and $n$ is the number of the constant coefficients. 
Both the above approaches used the $P L R \mathrm{~s}$ as the independent variables to directly/indirectly reduce the total power of the chillers. However, it is difficult to implement the PLR control in the real world application since the PLR can only be indirectly controlled. Some scholars improved the above approaches by replacing the PLRs with other relevant controllable parameters, such as the chilled water flow rates through each chiller $[6,40]$, the temperature set points of the chilled water leaving each chiller [41, 42], and the combination of the previous two parameters [43]. However, these approaches still have some limitations. For instance, the approaches of adjusting the chilled water flow rate through chillers can only be applied to the chiller plant equipped with chillers and pumps that can handle variable chilled water flow rates. In addition, these approaches only consider the impact of the load distribution on the chiller power. However, for plants with dedicated pumps and dedicated cooling tower for each chiller, the load distribution also impacts the pump power and the cooling tower power. Without considering the impacts on the pump power and the cooling tower power, these approaches can't guarantee the minimal energy consumption for the entire chiller plant.

The second group is associated with the optimization on the number of the operating chillers. As mentioned above, the conventional CLC uses the chillers' nominal cooling capacities to represent the chillers' actual cooling capacities. However, the actual cooling capacity of a chiller varies by its operating conditions [9, 21]. As shown in Figure 3, a chiller's capacity increases up to $110 \%$ of its nominal capacity when the temperature of the condenser water entering the chiller $\left(T_{c w, e n t}\right)$ decreases from $23.89^{\circ} \mathrm{C}$ (nominal condition) to $18.89^{\circ} \mathrm{C}$. Therefore, it is possible that a chiller's actual cooling capacity is larger than its nominal capacity and so does the entire multi-chiller plant. In this case, the chiller plant can meet a higher cooling load without turning on an additional chiller. Since we usually have a dedicated primary chilled water pump and a dedicated condenser water pump for each chiller, reducing the number of the operating chillers can save energy from the dedicated pumps [44]. 


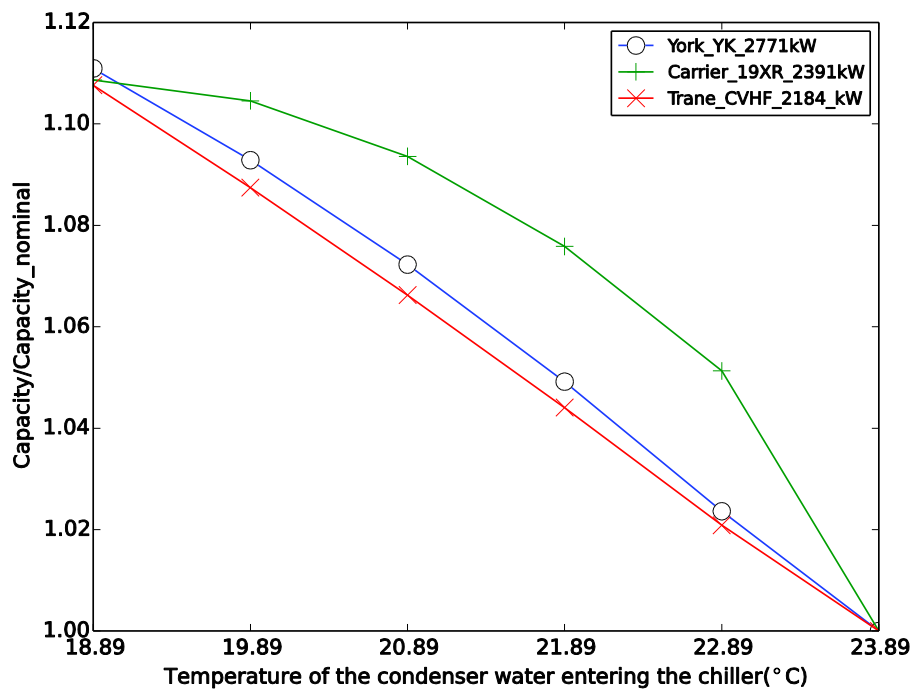

Figure 3 The relationship between the temperature of the condenser water entering the chiller and the relative cooling capacity for three different chillers calculated according to the chiller dataset provided by EnergyPlus [47]

To identify the optimal number of the operating chillers, some researchers proposed to reset the $C P \mathrm{~s}$ based on the estimation of the actual cooling capacity $[9,20,21]$. They calculated $C C_{a c t, i}$ using the operating parameters of the chiller (such as the pressure in the evaporator, compressibility factor and so on) at a given operating condition. Although these approaches may reduce the pump energy consumption, they can't guarantee the minimal energy consumption of the entire chiller plant including chillers, cooling towers and pumps. For instance, by increasing the $C P$ s according to the calculated cooling capacities, it is possible to reduce the number of the operating chillers. In that case, the PLR of each operating chiller has to increase to meet the same cooling load with fewer chillers. As we mentioned above, the increased $P L R$ s may lead to lower $C O P$ s.

To summarize, there are deficiencies in the existing CLC optimization approaches. In addition, although the optimization of the load distribution and the optimization of the number of the operating chillers interact with each other, they were only studied separately in previous studies. In response to these issues, we propose three new CLC optimization approaches. The first approach is to optimize the load distribution by adjusting the $C P$ s. The second approach is to optimize the number of the operating chillers by modulating the $C P$ s and the condenser water set point. The third approach combines the first two approaches aiming to achieve more energy savings with a holistic solution. 
This paper makes contributions to the literature in a number of ways: first, we developed a new approach for the optimal load distribution. This approach is easier to be implemented than existing approaches in literature and can achieve a better energy performance for the entire chiller plant. Second, we proposed a new approach to optimize the number of the operating chillers. This approach considers the impact of the $C P$ s reset on the energy performance of the chillers, the cooling towers and the pumps, which is not considered in the existing approaches. Third, we provided a holistic solution to address the optimal load distribution problem and the optimal number of the operating chillers problem simultaneously, which has not been reported in the literature yet to our knowledge.

The paper is organized as follows: after the introduction, we introduce the three new approaches for the CLC optimization. We then elaborate the implementation of these approaches. Finally, we evaluate the performances of these approaches via a case study.

\section{New Approaches for the CLC optimization}

\subsection{General Assumptions}

In this paper, we consider a water-cooled chiller plant with $M$ chillers and $N$ cooling towers. Each chiller has a dedicated constant speed chilled water pump and a dedicated constant speed condenser water pump. The towers have variable cooling tower fans controlled by the same set point for the temperature of the condenser water leaving the towers, which is called condenser water set point, $T_{c w, s e t}$. The other control parameters except the $C P$ s and $T_{c w, s e t}$, such as set points for the temperature of the chilled water leaving the chillers, $T_{c h w, s e t}$, are constant. Thus, the total power of chillers, pumps, and cooling towers, $P_{t o t}$, at time $t$ can be described as follows:

$$
\begin{gathered}
P_{t o t}(t)=\sum_{i}^{M}\left(P_{c h, i}(t)+P_{p u, i}(t)\right)+\sum_{j}^{N} P_{t w, j}(t) \\
=f_{1}\left(T_{c w, s e t}(t), C P_{1}(t), \ldots, C P_{M-1}(t), \dot{Q}(t), T_{w b}(t), \vec{S}(t)\right),
\end{gathered}
$$

where $P_{p u, i}$ and $P_{t w, j}$ is the power of the dedicated chilled water pump and the dedicated condenser water pump for the $i$ th chiller and the $j$ th cooling tower, respectively. The $T_{w b}$ is the wet bulb temperature and $\vec{S}$ is the state vector of the system (e.g. equipment operating status, water temperature in the condenser and the evaporator of the chiller). Then the energy consumption of the chiller plant for a period from $t_{0}$ to $t_{0}+\Delta t,\left.E_{t o t}\right|_{t_{0}} ^{t_{0}+\Delta t}$, is 


$$
\begin{gathered}
\left.E_{\text {tot }}\right|_{t_{0}} ^{t_{0}+\Delta t}=\int_{t_{0}}^{t_{0}+\Delta t} P_{t o t}(t) d t= \\
\int_{t_{0}}^{t_{0}+\Delta t} f_{1}\left(T_{c w, s e t}(t), C P_{1}(t), \ldots, C P_{M-1}(t), \dot{Q}(t), T_{w b}(t), \vec{S}(t)\right) d t
\end{gathered}
$$

The wet bulb temperature and the cooling load during the period of $\left[t_{0}, t_{0}+\Delta t\right]$ can be obtained from the weather forecast and by using regression models, respectively. Then we can use the predicted cooling load, $\dot{Q}^{P}$, and the predicted wet bulb temperature, $T_{w b}{ }^{P}$, to represent $\dot{Q}$ and $T_{w b}$ in the optimization:

$$
\begin{aligned}
\dot{Q}(t) & =\dot{Q}^{P}(t), \\
T_{w b}(t) & =T_{w b}^{P}(t) .
\end{aligned}
$$

We assumed $C P_{i}(t)$ and $T_{c w, s e t}(t)$ were constant during the period of $\left[t_{0}, t_{0}+\Delta t\right]$ :

$$
\begin{aligned}
T_{c w, s e t}(t) & =T_{c w, s e t}\left(t_{0}\right), \\
C P_{i}(t) & =C P_{i}\left(t_{0}\right)
\end{aligned}
$$

In addition, since $\vec{S}(t)$ is a function of $\vec{S}\left(t_{0}\right)$, equation (10) can be converted into:

$$
\left.E_{\text {tot }}\right|_{t_{0}} ^{t_{0}+\Delta t}=\int_{t_{0}}^{t_{0}+\Delta t} f_{2}\left(T_{c w, s e t}\left(t_{0}\right), C P_{1}\left(t_{0}\right), \ldots, C P_{M-1}\left(t_{0}\right), \dot{Q}^{P}(t), T_{w b}^{P}(t), \vec{S}\left(t_{0}\right)\right) d t .
$$

\subsection{The New Approaches}

\subsubsection{Approach 1: Optimal Load Distribution}

For the load distribution optimization, we assumed $T_{c w, s e t}$ is constant, thus equation (15) can be changed to:

$$
\left.E_{t o t}\right|_{t_{0}} ^{t_{0}+\Delta t}=\int_{t_{0}}^{t_{0}+\Delta t} f_{3}\left(C P_{1}\left(t_{0}\right), \ldots, C P_{M-1}\left(t_{0}\right), \dot{Q}^{P}(t), T_{w b}{ }^{P}(t), \vec{S}\left(t_{0}\right)\right) d t .
$$

We used the $C P \mathrm{~s}$ to replace $P L R \mathrm{~s}$ as the independent variables to minimize $\left.E_{t o t}\right|_{t_{0}} ^{t_{0}+\Delta t}$. Based on equation (16), the optimization problem can be defined as

$$
\begin{gathered}
J=\min \left(\left.E_{t o t}\right|_{t_{0}} ^{t_{0}+\Delta t}\right)= \\
\min \left(\int_{t_{0}}^{t_{0}+\Delta t} f_{3}\left(C P_{1}\left(t_{0}\right), \ldots, C P_{M-1}\left(t_{0}\right), \dot{Q}^{P}(t), T_{w b}{ }^{P}(t), \vec{S}\left(t_{0}\right)\right) d t\right), \\
\text { s.t. } \\
\qquad P_{1}^{\min }<C P_{1}\left(t_{0}\right) \leq \eta \sum_{j=1}^{1} C C_{n o m, j}, \\
C P_{i-1}\left(t_{0}\right)<C P_{i}\left(t_{0}\right) \leq \eta \sum_{j=1}^{i} C C_{n o m, j}(i>1),
\end{gathered}
$$

where $C P_{1}^{\text {min }}$ is the low bound for $C P_{1}\left(t_{0}\right)$. The $\dot{Q}^{P}(t), T_{w b}{ }^{P}(t)$ and $\vec{S}\left(t_{0}\right)$ are the input variables while $C P_{1}\left(t_{0}\right), \ldots, C P_{M-1}\left(t_{0}\right)$ are the independent variables in the optimization. Approach 1 does not consider 
the change of chiller cooling capacities by the operating conditions, thus the high bounds for CPs are determined as $\eta \sum_{j=1}^{i} C C_{n o m, j}$.

Compared to the existing optimal load distribution approaches [5, 7, 22-33], Approach 1 has the following advantages: first, it is easier for implementation since $C P$ s can be directly adjusted; second, the impact of the load distribution on the energy consumption by the cooling towers and the pumps is considered in the objective function. Thus, Approach 1 can lead to a better energy saving for the entire chiller plant.

\subsubsection{Approach 2: Optimal Number of the Operating Chillers}

For the cooling capacity based $C P$ s reset, we changed the reset into an optimization problem based on equation (15) to minimize $\left.E_{\text {tot }}\right|_{t_{0}} ^{t_{0}+\Delta t}$ :

$$
\begin{gathered}
J=\min \left(\left.E_{t o t}\right|_{t_{0}} ^{t_{0}+\Delta t}\right)= \\
\min \left(\int_{t_{0}}^{t_{0}+\Delta t} f_{2}\left(T_{c w, s e t}\left(t_{0}\right), C P_{1}\left(t_{0}\right), \ldots, C P_{M-1}\left(t_{0}\right), \dot{Q}^{P}(t), T_{w b}^{P}(t), \vec{S}\left(t_{0}\right)\right) d t\right), \\
\text { s.t. } \\
T_{c w, s e t, L} \leq T_{c w, s e t}\left(t_{0}\right) \leq T_{c w, s e t, H}, \\
\eta \sum_{j=1}^{i} C C_{n o m, j} \leq C P_{i}\left(t_{0}\right) \leq C P_{i}^{\max },
\end{gathered}
$$

where $T_{c w, s e t, L}$ and $T_{c w, s e t, H}$ is the low bound and the high bound for $T_{c w, s e t}\left(t_{0}\right), C P_{i}^{\max }$ is the high bound for $C P_{i}$. The $\dot{Q}^{P}(t), T_{w b}{ }^{P}(t)$ and $\vec{S}\left(t_{0}\right)$ are the input variables. The $T_{c w, s e t}$ is selected as an independent variable because $T_{c w, s e t}$ can be used to regulate $T_{c w, e n t}$ which in turn affects the actual cooling capacity of the chillers. The CPs can directly impact the number of the operating chillers and the associated pumps. To reduce the number of the operating chillers and the operating pumps, we used $\eta \sum_{j=1}^{i} C C_{n o m, j}$ as the low bound for $C P$ s and allowed $C P$ s to be higher values up to $C P_{i}^{\max }$.

Because the chiller cooling capacities vary by operating conditions, it is possible that we may not be able to provide sufficient cooling if the estimated $C P_{i}^{\max }$ is larger than the actual maximum capacity. In that case, we may save energy by reducing the number of the operating chillers and the associated pumps, but the thermal comfort in the demand side would be sacrificed since provided cooling is insufficient. We used the deviation of temperature of chilled water leaving the chiller, $T_{c h w, l e a}$, from $T_{c h w, s e t}$ as an indicator to determine if sufficient cooling is supplied. The deviation, $D_{c h w, l e a}$, is calculated by 


$$
D_{c h w, l e a}=\int_{t_{0}}^{t_{0}+\Delta t}\left|T_{c h w, l e a}(t)-T_{c h w, s e t}\right| d t
$$

Ideally, $D_{c h w, s e t}$ should be equal to 0 . However, the deviation may also be caused by the waiting time in the CLC which is inevitable. With that in mind, we designed the following constraint:

$$
D_{c h w, l e a} \leq D_{c h w, l e a, b a s e},
$$

where $D_{c h w, s e t, b a s e}$ is $D_{c h w, s e t}$ at the baseline in which no optimization occurs.

To summarize, the optimization can be described as:

$$
\begin{gathered}
J=\min \left(\left.E_{\text {tot }}\right|_{t_{0}} ^{t_{0}+\Delta t}\right)= \\
\min \left(\int_{t_{0}}^{t_{0}+\Delta t} f_{2}\left(T_{c w, s e t}\left(t_{0}\right), C P_{1}\left(t_{0}\right), \ldots, C P_{M-1}\left(t_{0}\right), \dot{Q}^{P}(t), T_{w b}{ }^{P}(t), \vec{S}\left(t_{0}\right)\right) d t\right) \\
\text { s.t. } \\
\qquad T_{c w, s e t, L} \leq T_{c w, \text { set }}\left(t_{0}\right) \leq T_{c w, s e t, H}, \\
\eta \sum_{j=1}^{i} C C_{n o m, j} \leq C P_{i}\left(t_{0}\right) \leq C P_{i}^{\max }, \\
D_{c h w, l e a} \leq D_{c h w, l e a, \text { base }} .
\end{gathered}
$$

Approach 2 considers the impact of the $C P$ s reset on the energy performance of the chillers, the cooling towers and the pumps. Thus it can guarantee the minimal energy consumption for the entire chiller plant, which may not be achieved by the existing $C P$ s reset approaches $[9,20,21]$.

\subsubsection{Approach 3: A Holistic Solution for the CLC}

It is possible to save more energy by combining Approach 1 and Approach 2. In this holistic approach, the CLC optimization problem can be defined as:

$$
\begin{gathered}
J=\min \left(\left.E_{\text {tot }}\right|_{t_{0}} ^{t_{0}+\Delta t}\right)= \\
\min \left(\int _ { t _ { 0 } } ^ { t _ { 0 } + \Delta t } f _ { 2 } \left(T_{c w, s e t}\left(t_{0}\right), C P_{1}\left(t_{0}\right), \ldots, C P_{M-1}\left(t_{0}\right), \dot{Q}^{P}(t), T^{2}\right.\right. \\
\text { s.t. } \\
T_{c w, \text { set }, L} \leq T_{c w, \text { set }}\left(t_{0}\right) \leq T_{c w, \text { set }, H}, \\
C P_{1}^{\text {min }}<C P_{1}\left(t_{0}\right) \leq C P_{1}^{\text {max }}, \\
C P_{i-1}\left(t_{0}\right)<C P_{i}\left(t_{0}\right) \leq C P_{i}^{\text {max }}(i>1), \\
D_{\text {chw,lea }} \leq D_{\text {chw,lea,base }} .
\end{gathered}
$$$$
\min \left(\int_{t_{0}}^{t_{0}+\Delta t} f_{2}\left(T_{c w, s e t}\left(t_{0}\right), C P_{1}\left(t_{0}\right), \ldots, C P_{M-1}\left(t_{0}\right), \dot{Q}^{P}(t), T_{w b}{ }^{P}(t), \vec{S}\left(t_{0}\right)\right) d t\right),
$$

The $\dot{Q}^{P}(t), T_{w b}{ }^{P}(t)$ and $\vec{S}\left(t_{0}\right)$ are the input variables while $T_{c w, s e t}\left(t_{0}\right), C P_{1}\left(t_{0}\right), \ldots, C P_{M-1}\left(t_{0}\right)$ are the independent variables. 


\subsection{Implementation}

\subsubsection{Constraints Setting}

The CLC optimizations described in Approach 1, Approach 2 and Approach 3 are all constrained optimization problems. The commonly used technologies for solving the constrained optimization problems include the barrier function method and the penalty function method [48]. On one hand, the barrier function method imposes a punishment on the value of the objective function if the value of the objective function approaches the feasible region boundary. On the other hand, the penalty function method adds a term to the objective function and the added term generates a negative impact on the objective function when constrains are violated. In our CLC optimization, $T_{c w, s e t}\left(t_{0}\right)$ and/or $C P_{i}\left(t_{0}\right)$, which make $D_{c h w, l e a}=D_{c h w, l e a, b a s e}$, can be optimal values, which is not allowed in the barrier function method. Thus, we adopted the penalty function method. For example, the optimization problem in Approach 3 can be converted into:

$$
\begin{gathered}
J^{*}=\min \left(\int_{t_{0}}^{t_{0}+\Delta t} f_{2}\left(T_{c w, s e t}\left(t_{0}\right), C P_{1}\left(t_{0}\right), \ldots, C P_{M-1}\left(t_{0}\right), \dot{Q}^{P}(t), T_{w b}{ }^{P}(t), \vec{S}\left(t_{0}\right)\right) d t+k .\right. \\
\left.\max \left(0, D_{\text {chw,lea }}-D_{\text {chw,lea,base }}\right)\right),
\end{gathered}
$$

s.t.

$$
\begin{gathered}
T_{c w, s e t, L} \leq T_{c w, s e t}\left(t_{0}\right) \leq T_{c w, s e t, H}, \\
C P_{1}^{\text {min }}<C P_{1}\left(t_{0}\right) \leq C P_{1}^{\text {max }}, \\
C P_{i-1}\left(t_{0}\right)<C P_{i}\left(t_{0}\right) \leq C P_{i}^{\max }(i>1),
\end{gathered}
$$

where $k$ is the iteration index of one optimization and $\max \left(0, D_{\text {chw,lea }}-D_{\text {chw,lea,base }}\right)$ is the term for the penalty function method.

\subsubsection{Optimization Framework}

To enable the CLC optimization described in Section 2.2, we developed an optimization framework (Figure 4). The $\dot{Q}^{P}(t), T_{w b}{ }^{P}(t)$ and $\vec{S}\left(t_{0}\right)$ are used as input variables. Then the generated optimal $C P_{i}\left(t_{0}\right)$ and/or $T_{c w, s e t}\left(t_{0}\right)$ will then be used to obtain $\vec{S}\left(t_{0}+\Delta t\right)$ as initial values for the next optimization period starting from $t_{0}+\Delta t$. 


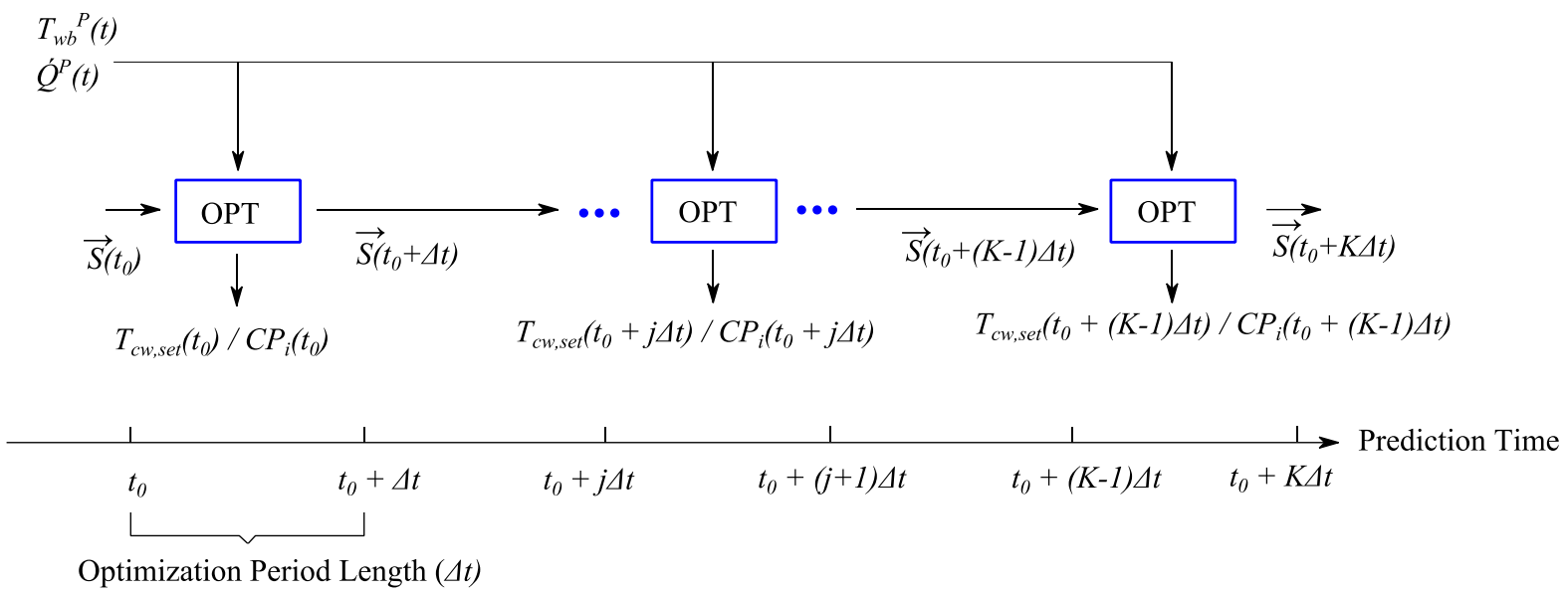

Figure 4 The optimization framework

\section{Case Study}

\subsection{Case Description}

\subsubsection{Configuration of the Chiller Plant}

We studied a chiller plant with three identical chillers, three identical chilled water pumps, three identical condenser water pumps, and three identical cooling towers (show in Figure 5). Each chiller has one dedicated chilled water pump, one dedicated condenser water pump and one dedicated cooling tower. The model of the chiller is a York_YK2771kW, which has the nominal cooling capacity as 2,771 kW (788 ton). For the cooling tower, the nominal fan power is $37 \mathrm{~kW}$ (50 HP) and was assumed to be proportional to the cubic of the fan speed ratio. The nominal wet bulb temperature and the nominal approach temperature is $23.89^{\circ} \mathrm{C}\left(75.00^{\circ} \mathrm{F}\right)$ and $0.89^{\circ} \mathrm{C}\left(1.60^{\circ} \mathrm{F}\right)$, respectively. The chilled water and the condenser water pumps are constant speed pumps and their powers are $34 \mathrm{~kW}$ and $47 \mathrm{~kW}$, respectively. In the condenser water loop, a three-way valve is employed to modulate the condenser flow rates through the cooling towers so that the temperature of the condenser water entering the chiller, $T_{c w, e n t}$ will not be less than $12.78^{\circ} \mathrm{C}\left(55.00^{\circ} \mathrm{F}\right)$, which is the lowest $T_{c w, e n t}$ can be accepted by the chillers. 


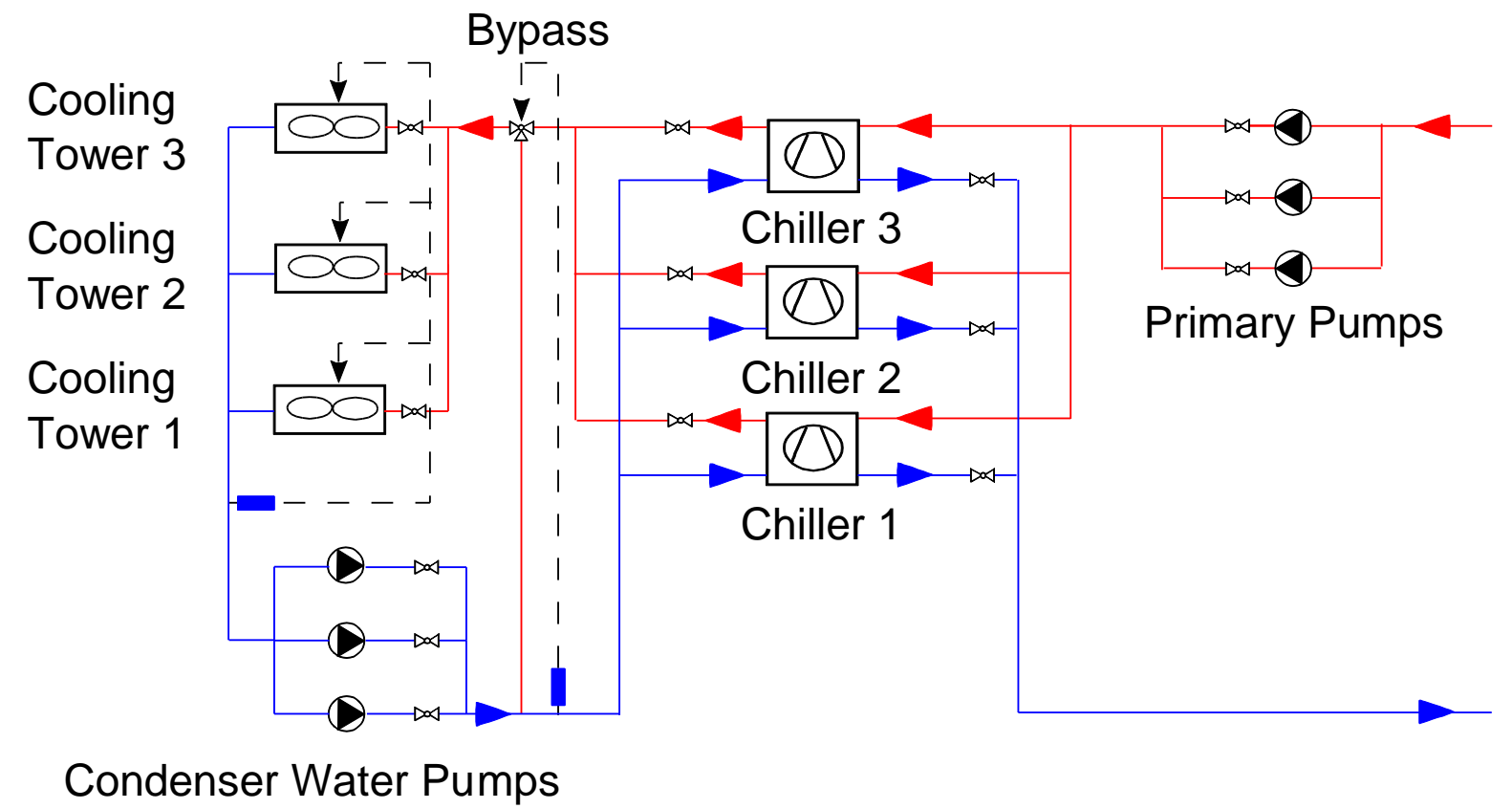

\section{Temperature Sensor}

Figure 5 The schmatic of the studied chiller plant

A supervisor controller is used to control the chiller operation status according to the measured cooling load. The control sequence is described as Figure 1 with $C P_{1}$ and $C P_{2}$ fixed as 709 ton and 1,418 ton, respectively. The dead band (50 ton) and a waiting period (900 s) are also applied.

\subsubsection{System Model}

In this study, we used Modelica, which is an equation-based object-orient modeling language, to establish the system model. Modelica is very suitable for modeling the multi-domain systems [13, 49-51] such as the chiller plants that contain not only the physical system but also the control system.

In this study, the Modelica Buildings library [49] and the Modelica_StateGraph2 library [52] were used to model the chiller plant system. In this model, $\dot{Q}$ and $T_{w b}$ data is read externally. The performance curve of York_YK2771kW from the chiller dataset provided by EnergyPlus [47] was adapted in the chiller model. The detail of the system model can referred to [53]. 


\subsubsection{Optimization Setting}

In this study, we used the Hooke Jeeves algorithm [54] in the GenOpt [55] optimization engine to perform the searching of the optimal $C P \mathrm{~s}$ and the optimal condenser water set point. The optimization was set to be performed every day. We set the safety factor $\eta=90 \%$ for all proposed approaches. For Approaches 2 and 3, we set the lowest allowable condenser water set point to be $13.89^{\circ} \mathrm{C}$ and $C P_{i}^{\max }$ to be $1.1 C C_{n o m}$. The intervals for $T_{c w, s e t}, C P_{1}$ and $C P_{2}$ are $1^{\circ} \mathrm{C}, 78.8$ ton and 78.8 ton, respectively. Table 1 summaries the settings used in the baseline and proposed approaches.

Table 1 Settings for each CLC optimization approach

\begin{tabular}{|c|c|c|c|}
\hline CLC Optimization Approaches & $\boldsymbol{T}_{\boldsymbol{c w}, \boldsymbol{s e t}}\left[{ }^{\mathbf{0}} \mathrm{C}\right]$ & $\boldsymbol{C P}_{\mathbf{1}}$ [ton] & $\boldsymbol{C P}_{\mathbf{2}}$ [ton] \\
\hline Baseline & \multirow{2}{*}{ Fixed as 23.89 } & 709 & 1418 \\
\cline { 3 - 4 } & & {$[0,709]$} & {$\left[C P_{1}, 1,418\right]$} \\
\hline Approach 1 & \multirow{2}{*}[13.89,23.89]{} & {$[709,867]$} & {$[1,418,1,734]$} \\
\cline { 4 - 4 } & & {$[0,867]$} & {$\left[C P_{1}, 1,734\right]$} \\
\hline Approach 2 & &
\end{tabular}

We used real historic data for $\dot{Q}$ and $T_{w b}$ from an actual chiller plant in Washington D.C. as the input variables for the optimization. The $\dot{Q}$ is from on-site measurement and $T_{w b}$ is from a nearby weather station [56]. Since both $\dot{Q}$ and $T_{w b}$ are hourly data, they were linearly interpolated during one hour for provide the inputs for the dynamic simulation. This is equivalent to have perfect prediction models that can provide reference inputs to evaluate the optimization approaches with less impact factors. In real world implementation, one can obtain the predicted cooling load by using regression models and the wet bulb temperature from weather forecast.

\subsection{Results}

\subsubsection{Annual Simulation}

Figure 6 shows the annual energy saving of the three CLC optimization approaches compared to the baseline. Approach 1 could reduce the annual chiller energy consumption by $4.9 \%$. However, the energy consumption of the cooling towers and the pumps were increased $(-5.8 \%$ and $-8.6 \%$ in saving, respectively). Thus, the total energy saving ratio was only $0.5 \%$. Approach 2 achieved a total energy saving around 5.3\%. The energy use of the chillers and the pumps was reduced by $8.6 \%$ and $2.0 \%$, respectively. Meanwhile, the cooling tower energy use was significantly increased (-41.8\% in saving). As expected, Approach 3 provided the highest annual total energy saving (around 5.6\%). The chiller energy 
saving ratio was the highest as $11.8 \%$ with the cost of the highest cooling tower energy consumption ($43.8 \%$ in saving). In addition, the pump energy also rose slightly ( $-3.7 \%$ in saving).
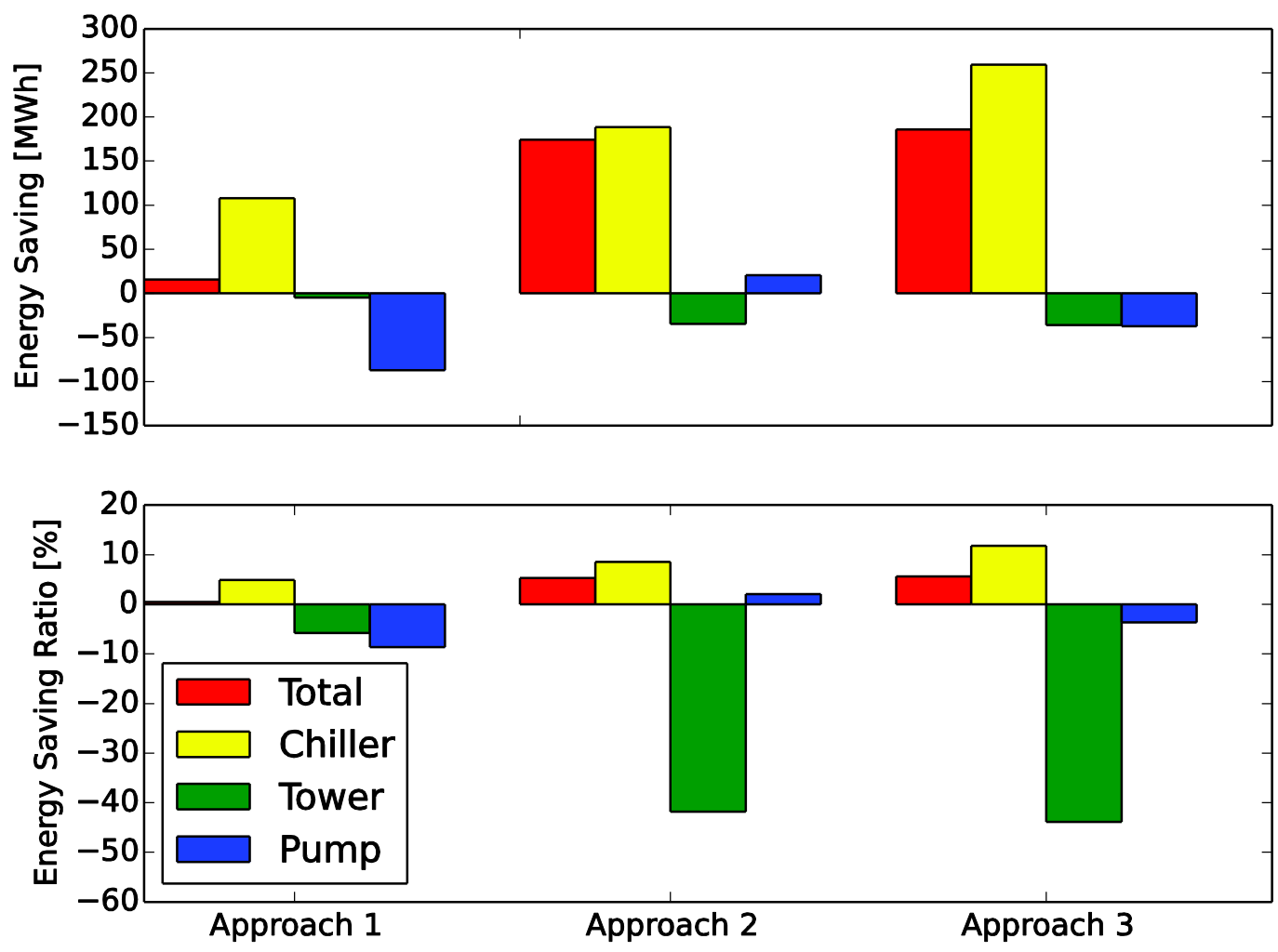

Figure 6 Comparison of the energy savings by different approaches

To understand when the energy saving occurred, we show the detailed analysis. As shown in Figure 7, the chiller energy consumption was saved mainly in the summer (May to September) for Approach 1. The cooling tower energy consumption was sometimes decreased and sometimes increased. The pump energy consumption was increased in the summer, which indicates that the number of the operating chillers was mainly increased to achieve an optimal load distribution. The total energy consumption was decreased mainly in the summer. However, at a very few days, the total energy consumption was even increased. The explanation is that the initial values of the state vectors (such as the chiller operating status) were different from that in the baseline at these days. Thus, it is possible that Approach 1 may generate higher total energy consumption. For example, in October 27, there were two chillers operating at the beginning for Approach 1 while there was only one for the baseline. The total energy consumption increased for Approach 1 compared with the baseline is around $0.2 \%$. 

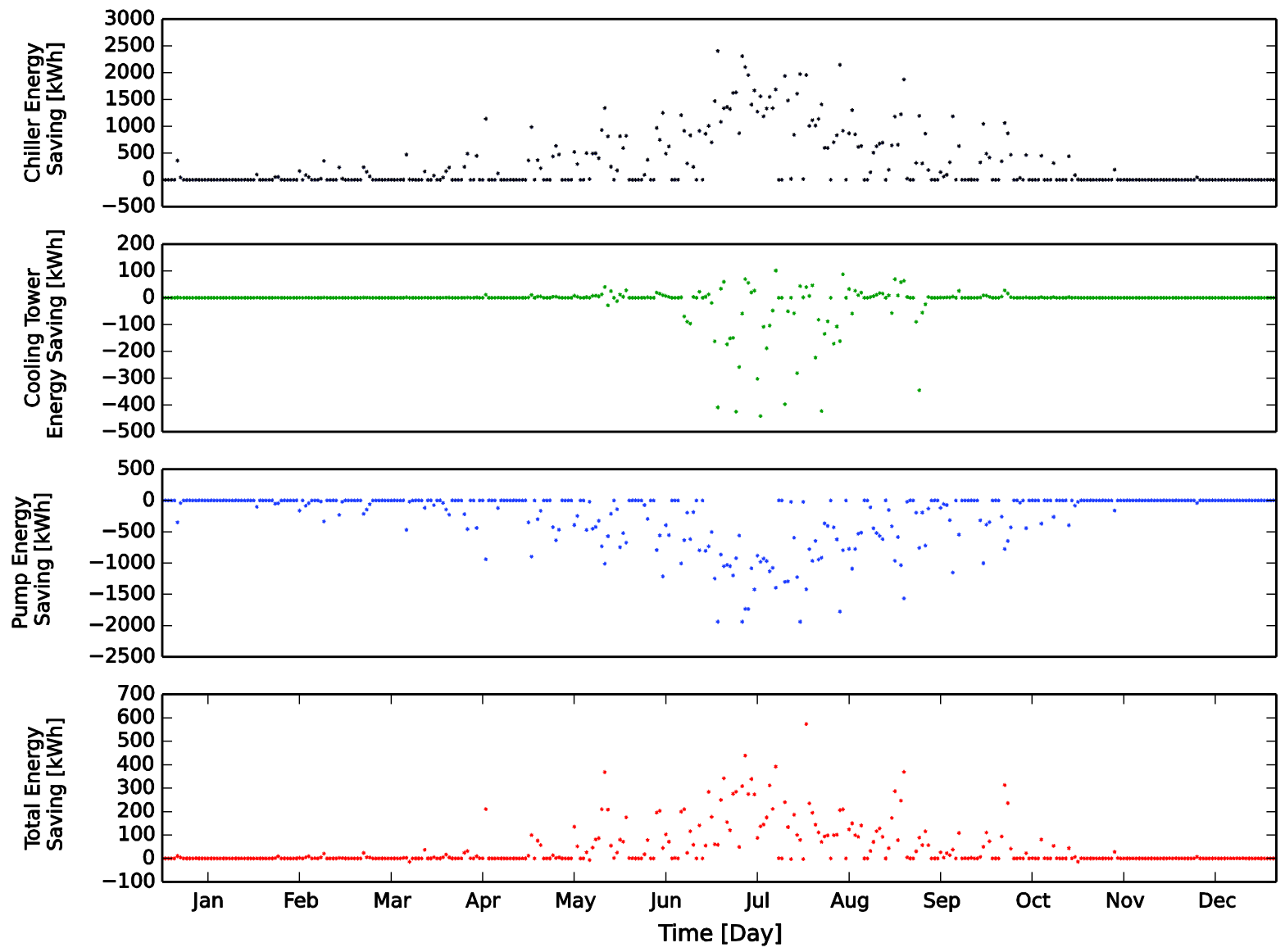

Figure 7 Daily energy saving by Approach 1

For Approach 2, the chiller energy consumption was saved mainly in the non-summer season (Figure 8). The cooling tower energy consumption was increased in the non-summer season due to the lower $T_{c w, s e t}$. The pump energy consumption was also saved in the non-summer season, which implies that the number of the operating chillers was mainly decreased. Since the studied chillers have higher efficiency at the part loads thus the energy saving from the chiller should be mainly due to the lower $T_{c w, e n t}$. 

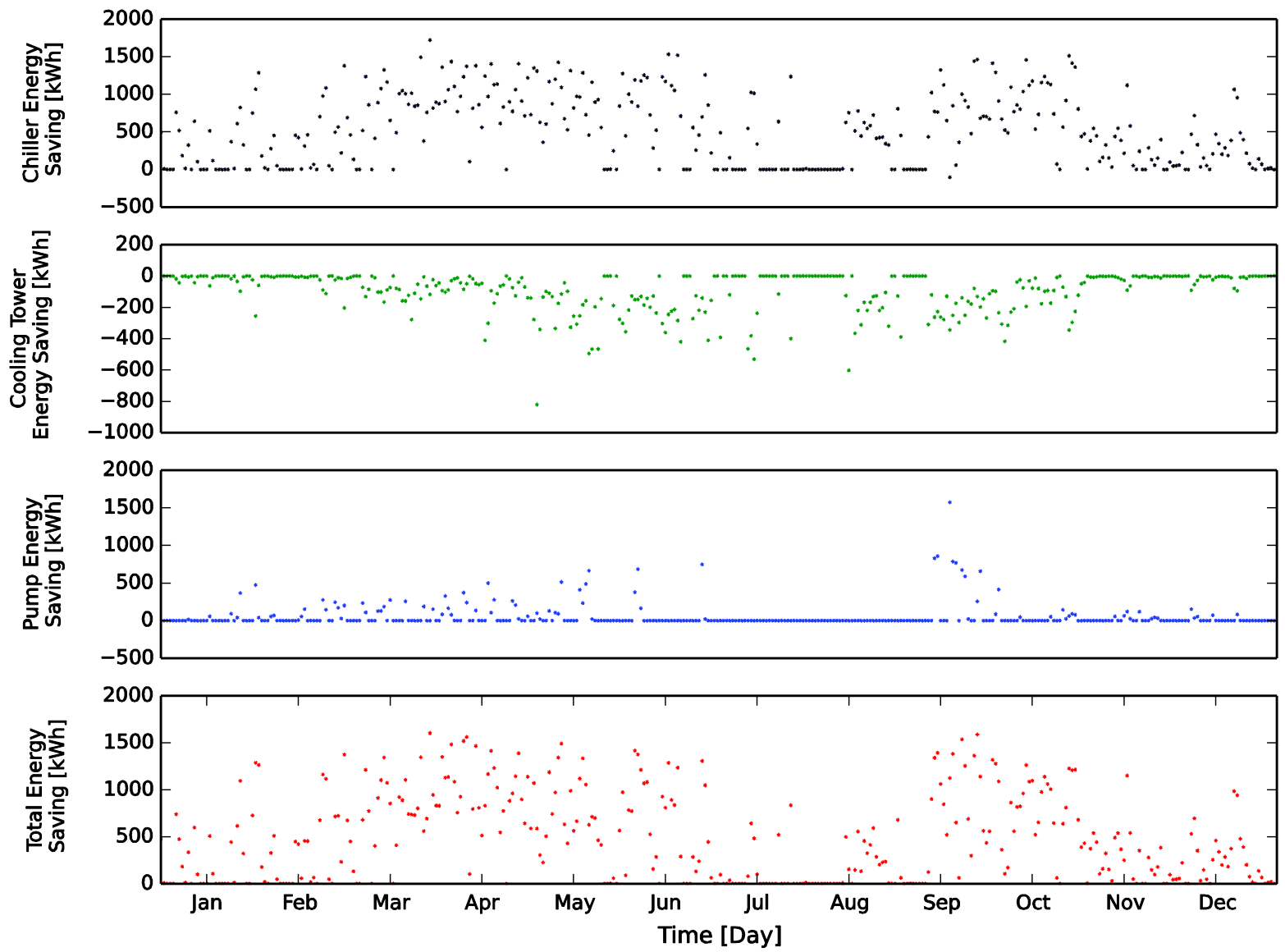

Figure 8 Daily energy saving by Approach 2

As shown in Figure 9, the chiller energy consumption was saved for the most of time in the studied year for Approach 3, which could be attributed to both the optimal load distribution and the lower $T_{c w, e n t}$. The cooling tower energy consumption was mostly increased. It is also interesting to see that cooling tower energy consumption was reduced sometimes in the summer. The pump energy consumption was increased or reduced around the year. In the summer, the pump energy consumption was usually increased which indicates that more chillers were operating compared with the baseline. In the rest time, the pump energy consumption was reduced which means the cooling load was met with less chillers. 


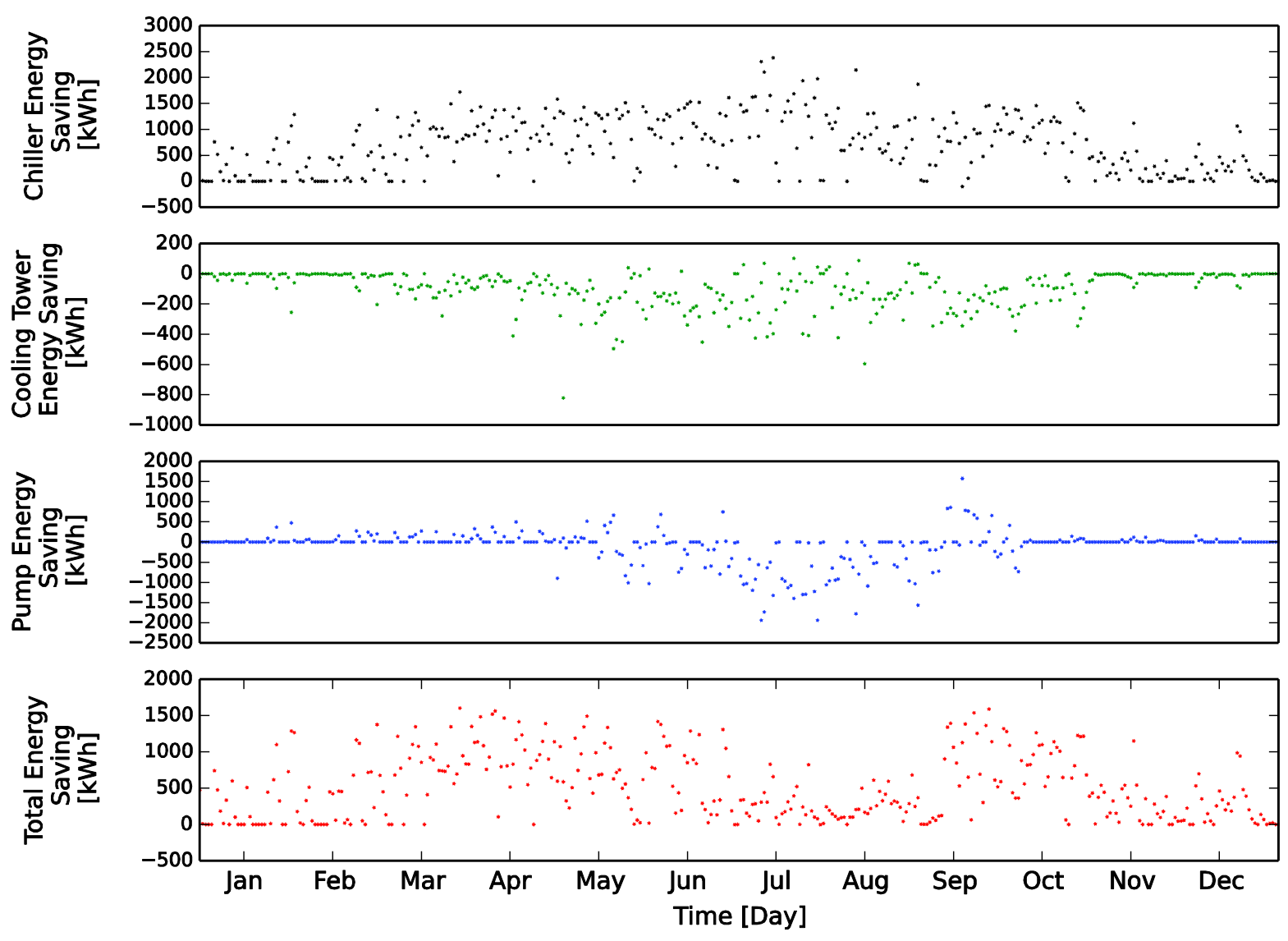

Figure 9 Daily energy saving by Approach 3

Based on the above analysis, we could find that:

- Approach 1's energy savings from chillers was mostly offset by the increased energy used by the pumps. This means that the optimal load distribution approach should be performed on chiller plants with high efficiency condenser water pumps and high efficiency chilled water pumps.

- Approach 2 can save the pump energy for about $2.0 \%$ and the chiller energy use for about $8.6 \%$. The pump energy use decreased because of the reducing number of the operating chillers while the chiller energy use saving was mainly due to the lower temperature of the condenser water entering the chiller.

- Approach 3 can increase the energy saving by combining the previous two approaches, but the total energy saving is less than the summation of their savings. Approach 3 can save the energy used by the chillers, the cooling towers as well as the pumps. In the summer, it increased the number of the operating chillers to save energy for the chillers and the cooling towers. In the non- 
summer season, it reduced the operating chiller number so that the pump energy saving can be obtained.

\subsubsection{Typical Days}

In order to further identify how energy saving for different components was achieve at different seasons, we analyzed the performance of Approach 3 for one non-summer day and one summer day. As shown in Figure 10, the cooling load in the non-summer day (April 9) ranged from around 400 ton to 800 ton and the wet bulb temperature was within the range from around $5^{\circ} \mathrm{C}$ to $10^{\circ} \mathrm{C}$. The optimal $C P_{1}$ and $C P_{2}$ predicted by Approach 3 were 867 ton and 1,418 ton while the optimal $T_{c w \text {,set }}$ was $13.89^{\circ} \mathrm{C}$. Since the cooling load was always lower than 817 ton, there was only one chiller operating for Approach 3. However, for the baseline, since the cooling load was larger than 759 ton at around 13:00, the number of the operating chillers increased to 2 accordingly and then decreased to 1 around 17:00 when the cooling load was less than 659 ton. There was almost no deviation of $T_{c h w, l e a}$ from $T_{c h w, s e t}$ for both Approach 3 and the baseline.
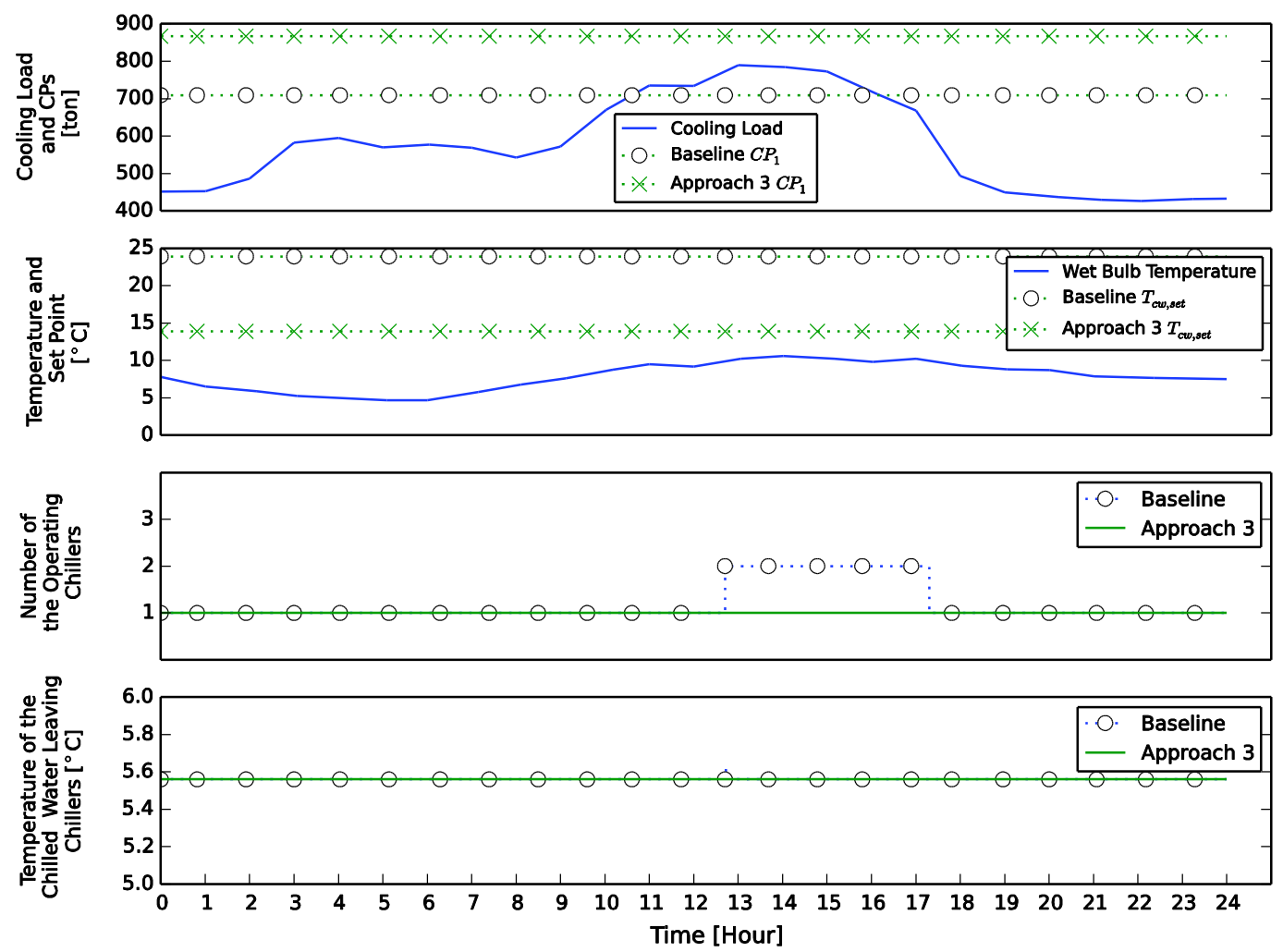

Figure 10 Simulated system statuses for a non-summer day 
As shown in Figure 11, the hourly chiller energy consumption by Approach 3 is significantly less than the baseline over the day since the chiller is more efficient with a cooler condenser water achieved by lowering the $T_{c w, s e t}$. However, having a lower $T_{c w, s e t}$ significantly increased the cooling tower energy consumption. The pump energy was the same for Approach 3 as that for the baseline except the period when there was two operating chillers for the baseline. Since the chiller energy consumption and the pump energy consumption dominate the chiller plant energy consumption, Approach 3 always required less energy consumption than the baseline.
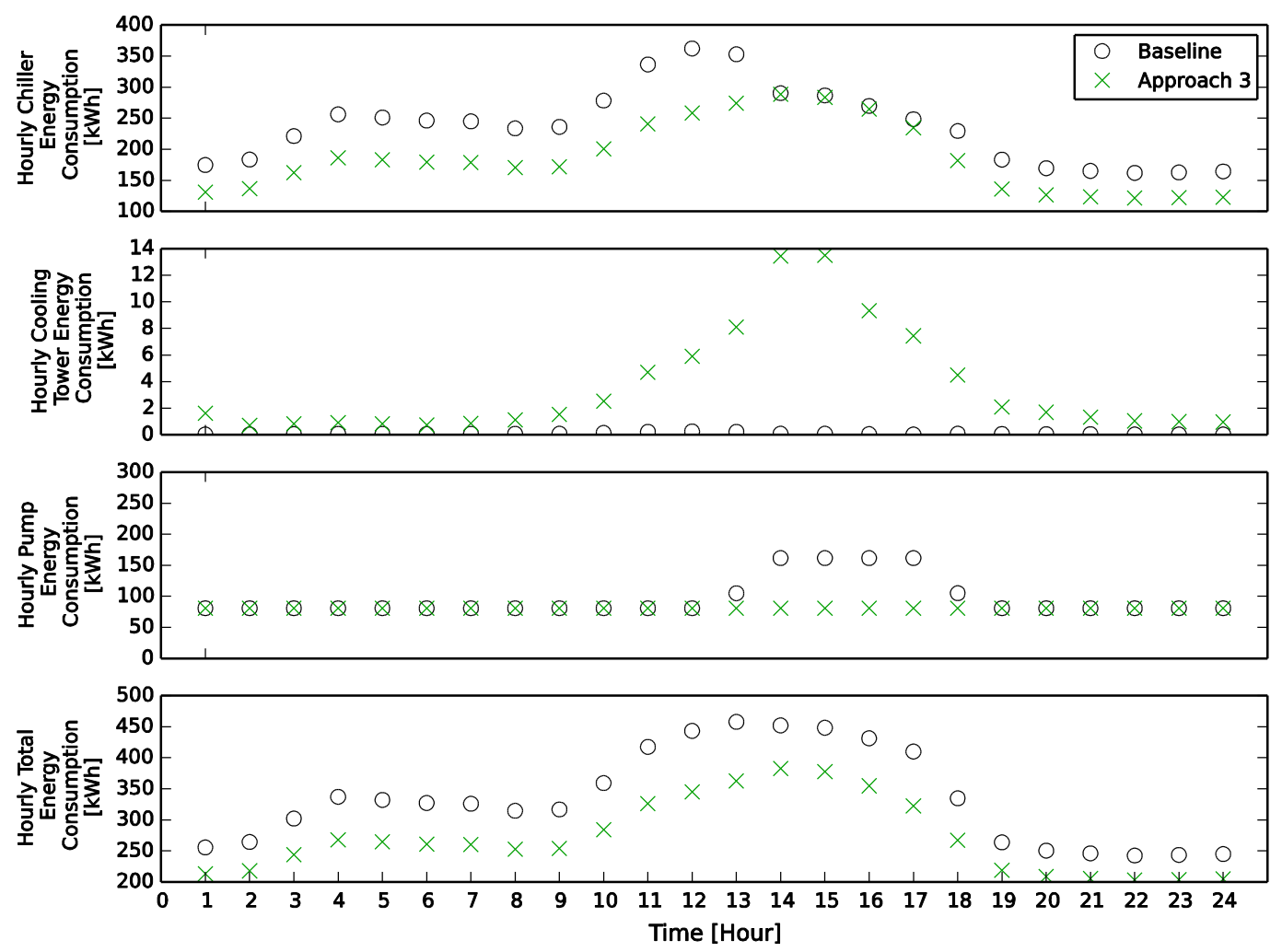

Figure 11 Simulated energy consumptions for a non-summer day

As shown in Figure 12, the cooling load in the summer day (July 20) ranged from around 1,000 ton to 1,500 ton and the wet bulb temperature was within the range from around 20 to $25^{\circ} \mathrm{C}$. The optimal $C P_{1}$ and $C P_{2}$ predicted by Approach 3 were 709 ton and 1,182 ton compared to the baseline value of 709 ton and 1,418 ton. The optimal $T_{c w, s e t}$ predicted by Approach 3 was $23.89^{\circ} \mathrm{C}$ which was the same as the baseline. At the beginning, there were three chillers operating for Approach 3. The cooling load decreased to be less than 1,132 ton at around 19:00 and one of the operating chillers was turned off. For the baseline, the number of the operating chillers was two at the beginning and then turned to three at 
around 14:00. At around 15:30, it turned back to two. No significant deviation of $T_{c h w, l e a}$ from $T_{c h w, s e t}$ for both Approach 3 and the baseline was observed.

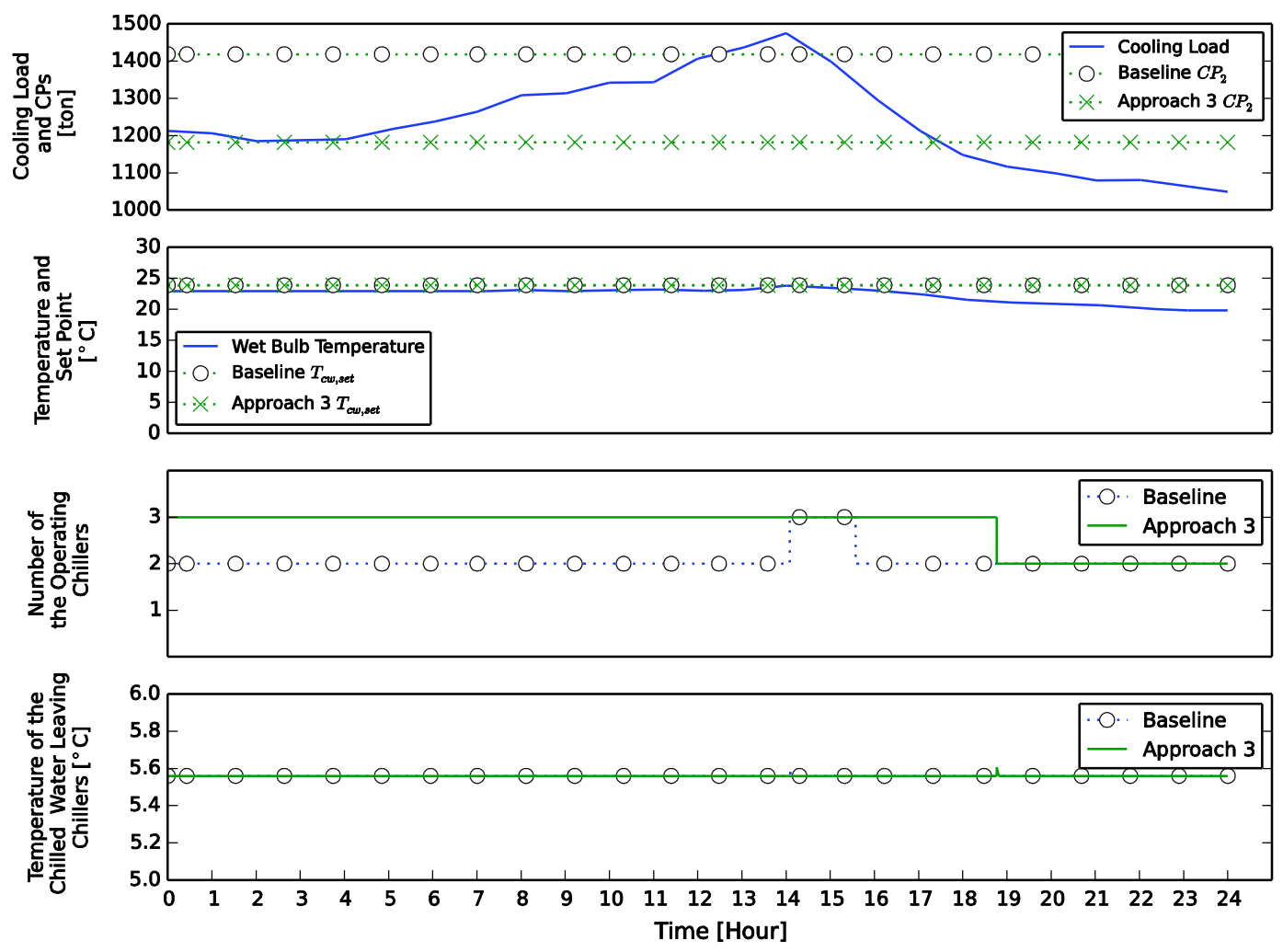

Figure 12 Simulated system statuses for a summer day

As shown in Figure 13, the hourly chiller consumption for Approach 3 was significantly less than that for the baseline mostly because the chillers are more efficient at lower PLRs enabled by an additional chiller. When the number of the operating chillers was the same (e.g. 20:00-24:00), the chiller energy were the same for both Approach 3 and the baseline.

The cooling tower energy consumption was smaller for Approach 3 than that for the baseline for most of the day since running three towers at lower speed is more energy efficient than running two towers at a higher speed. However, in the period from 14:00 to 16:00, the cooling tower energy consumption for the baseline was smaller. The reason is that at this period, the wet bulb temperature was relatively higher and the cooling towers were not able to maintain $T_{c w, e n t}$ as the set point. In that case, adding the number of the operating cooling towers would not affect the load ratio of each cooling tower (always be full load) and thus the cooling tower energy consumption was increased as a result. 
The pump energy was mostly higher for Approach 3 than that for the baseline because additional pumps was running for the additional chiller. However, the total energy consumption for Approach 3 was smaller than that in the baseline for the most time of the day because the energy saving from the chillers and the cooling towers can offset the additional energy consumption by the pumps.
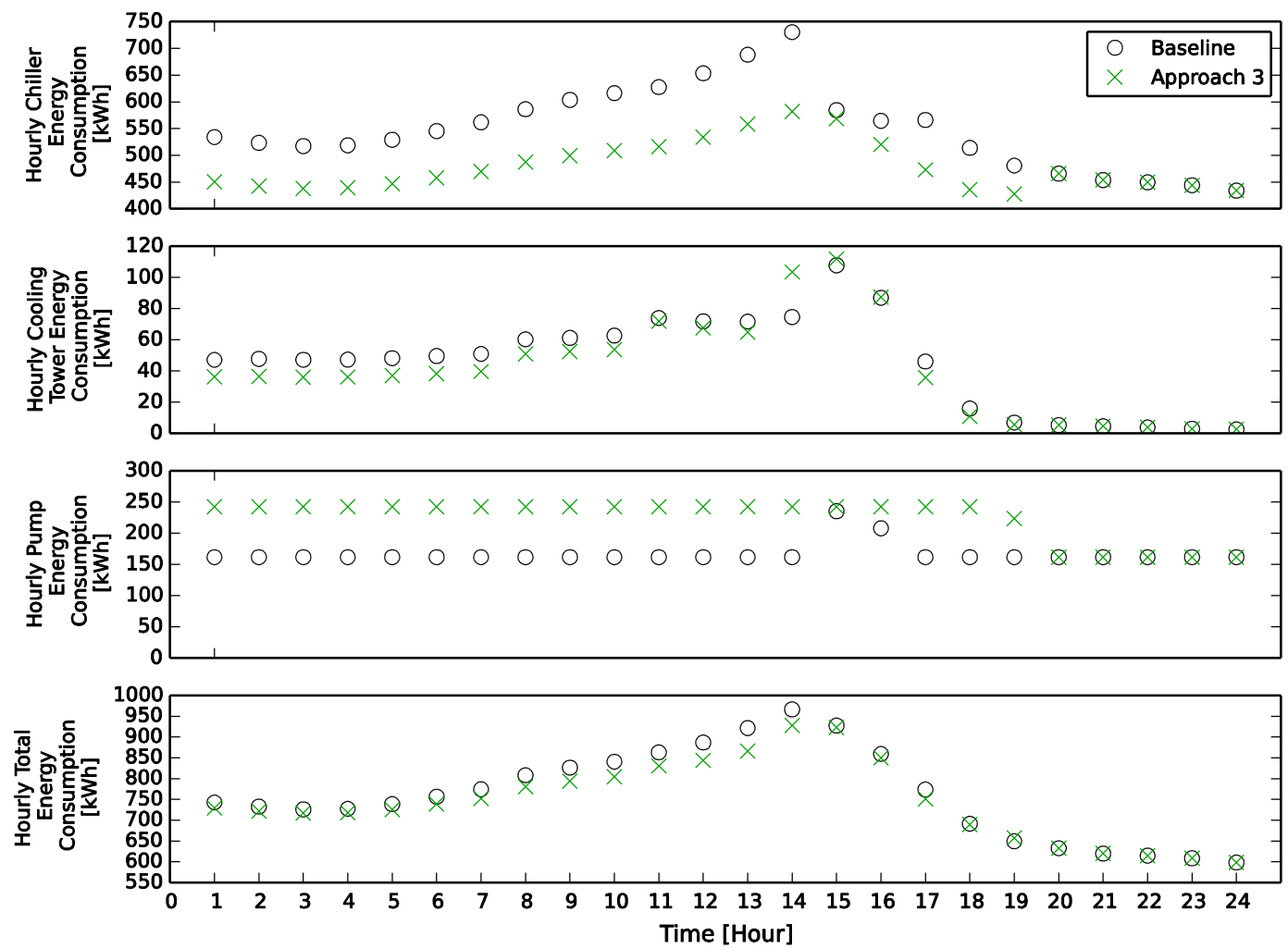

Figure 13 Simulated energy consumptions for a summer day

\section{Conclusion}

In this study, we proposed three new CLC optimization approaches to enhance the CLC. Approach 1 is to optimize the load distribution by adjusting the $C P$ s. Approach 2 is to optimize the number of the operating chillers by modulating the $C P$ s and the condenser water set point. Approach 3 is the combination of the first two approaches. The results suggest that the three approaches for optimizing the chiller sequencing control can all result in energy savings with little risk. The results also suggest that one needs to look at both the energy savings in the chillers as well as the increased energy used of other components of the chiller plant in the chiller sequencing control optimization. Among the three approaches, Approach 3 achieved the highest energy saving because it considered the trade-off among the energy consumption by the chillers, the cooling towers and the pumps. In the summer, we can make more 
chillers operating to achieve higher energy efficiency for the chillers and the cooling towers. In the nonsummer season, we can reduce the number of the operating chillers to save the pump energy consumption.

The new CLC optimization approaches can be directly implemented in the real chiller plant for resetting the $C P$ s and/or the condenser water set point. They can also be used as references to help the operators manually adjust the chiller sequencing control.

It should be noted that the evaluation of the three approaches was limited to the application in the chiller plants with a constant primary chilled water flow rate and identical chillers in this study. In future study, we can assess the performance of three approaches for chiller plants with variable primary chilled water flow rates and non-identical chillers.

\section{Acknowledgement}

This research was supported by the U.S. Department of Defense under the ESTCP program. The authors thank Marco Bonvini, Michael Wetter, Mary Ann Piette, Jessica Granderson, Oren Schetrit, Rong Lily $\mathrm{Hu}$ and Guanjing Lin for the support provided through the research.

This research also emerged from the Annex 60 project, an international project conducted under the umbrella of the International Energy Agency (IEA) within the Energy in Buildings and Communities (EBC) Programme. Annex 60 will develop and demonstrate new-generation computational tools for building and community energy systems based on Modelica, Functional Mockup Interface and BIM standards.

\section{Reference}

[1] U.S. Department of Energy. Buildings Energy Data Book. <https://catalog.data.gov/dataset/buildingsenergy-data-book> (accessed May 15. 2014).

[2] Westphalen D, Koszalinski S. Energy Consumption Characteristics of Commercial Building HVAC Systems Volume I : Chillers, Refrigerant Compressors,and Heating Systems. Arthur D. Little, Inc.; 2001.

[3] Braun JE, Diderrich GT. Near-optimal Control of Cooling Towers for Chilled-water Systems. ASHRAE Trans 1990;96(2):806-16.

[4] Chang CC, Shieh SS, Jang SS, Wu CW, Tsou Y. Energy Conservation Improvement and ON-OFF Switch Times Reduction for An Existing VFD-fan-based Cooling Tower. Appl Energ 2015;154(2015):491-9. 
[5] Chang YC. A Novel Energy Conservation Method - Optimal Chiller Loading. Electr Pow Syst Res 2004;69(2-3):221-6.

[6] Yu FW, Chan KT. Optimum Load Sharing Strategy for Multiple-chiller Systems Serving Airconditioned Buildings. Build Environ 2007;42(4):1581-93.

[7] Lee WS, Lin LC. Optimal Chiller Loading by Particle Swarm Algorithm for Reducing Energy Consumption. Appl Therm Eng 2009;29(8-9):1730-4.

[8] Chua KJ, Chou SK, Yang WM, Yan J. Achieving Better Energy-efficient Air Conditioning - a Review of Technologies and Strategies. Appl Energ 2013;104(2013):87-104.

[9] Li Z, Huang G, Sun Y. Stochastic Chiller Sequencing Control. Energ Buildings 2014;84(2014):203-13.

[10] Lu L, Cai W, Soh YC, Xie L, Li S. HVAC System Optimization - Condenser Water Loop. Energ Convers Manage 2004;45(4):613-30.

[11] Ma Z, Wang S, Xu X, Xia F. A Supervisory Control Strategy for Building Cooling Water Systems for Practical and Real Time Applications. Energ Convers Manage 2008;49(8):2324-36.

[12] Lee KP, Cheng TA. A Simulation-optimization Approach for Energy Efficiency of Chilled Water System. Energ Buildings 2012;54(2012):290-6.

[13] Huang S, Zuo W. Optimization of the Water-cooled Chiller Plant System Operation. In: Proceedings of ASHRAE/IBPSA-USA Building Simulation Conference, Atlanta, GA, U.S.A., 2014. p. 300-7.

[14] Sun J, Reddy A. Optimal Control of Building HVAC\&R Systems using Complete Simulation-based Sequential Quadratic Programming (CSB-SQP). Build Environ 2005;40(5):657-69.

[15] Yu FW, Chan KT. Optimization of Water-cooled Chiller System with Load-based Speed Control. Appl Energ 2008;85(2008):931-50.

[16] Zhang Z, Li H, Turner WD, Deng S. Optimization of the Cooling Tower Condenser Water Leaving Temperature using a Component-based Model. ASHRAE Trans 2011;117(1):934-44.

[17] A.Tirmizi S, P.Gandhidasan, M.Zubair S. Performance Analysis of a Chilled Water System with Various Pumping Schemes. Appl Energ 2012;100(2012):238-48.

[18] Ma Z, Wang S. Supervisory and Optimal Control of Central Chiller Plants using Simplified Adaptive Models and Genetic Algorithm. Appl Energ 2011;88(1):198-211.

[19] Ma Z, Wang S, Xiao F. Online Performance Evaluation of Alternative Control Strategies for Building Cooling Water Systems Prior to In Situ Implementation. Appl Energ 2009;86(2009):712-21.

[20] Sun Y, Wang S, Huang G. Chiller Sequencing Control with Enhanced Robustness for Energy Efficient Operation. Energ Buildings 2009;41(11):1246-55.

[21] Sun Y, Wang S, Xiao F. In Situ Performance Comparison and Evaluation of Three Chiller Sequencing Control Strategies in a Super High-rise Building. Energ Buildings 2013;61(2013):333-43. 
[22] Chang YC, Lin FA, Lin CH. Optimal Chiller Sequencing by Branch and Bound Method for Saving Energy. Energ Convers Manage 2005;46(13-14):2158-72.

[23] Chang YC, Lin JK, Chuang MH. Optimal Chiller Loading by Genetic Algorithm for Reducing Energy Consumption. Energ Buildings 2005;37(2):147-55.

[24] Chang YC. An Outstanding Method for Saving Energy - Optimal Chiller Operation. IEEE Trans Energy Convers 2006;21(2):527-32.

[25] Chang YC. An Innovative Approach for Demand Side Management-Optimal Chiller Loading by Simulated Annealing. Energ 2007;31(12):1883-96.

[26] Ardakani AJ, Ardakani FF, Hosseinian SH. A Novel Approach for Optimal Chiller Loading using Particle Swarm Optimization. Energ Buildings 2008;40(12):2177-87.

[27] Chang YC, Lee CY, Chen CR, Chou CH, Chen WH, Chen WH. Evolution Strategy based Optimal Chiller Loading for Saving Energy. Energ Convers Manage 2009;50(1):132-9.

[28] Fan B, Jin X, Du Z. Optimal Control Strategies for Multi-chiller System based on Probability Density Distribution of Cooling Load Ratio. Energ Buildings 2011;43(10):2813-21.

[29] Geem ZW. Solution Quality Improvement in Chiller Loading Optimization. Appl Therm Eng 2011;31(10):1848-51.

[30] Chen CL, Chang YC, Chan TS. Applying Smart Models for Energy Saving in Optimal Chiller Loading. Energ Buildings 2014;68 Part A(2014):364-71.

[31] Coelho LdS, Mariani VC. Improved Firefly Algorithm Approach Applied to Chiller Loading for Energy Conservation. Energ Buildings 2013;59(2013):273-8.

[32] Coelho LdS, Klein CE, Sabat SL, Mariani VC. Optimal Chiller Loading for Energy Conservation using a New Differential Cuckoo Search Approach. Energ 2014;75(2014):237-43.

[33] Chang YC. Optimal Chiller Loading by Evolution Strategy for Saving Energy. Energ Buildings 2007;39(4):437-44.

[34] Abou-Ziyan HZ, Alajmi AF. Effect of Load-sharing Operation Strategy on the Aggregate Performance of Existed Multiple-chiller Systems. Appl Energ 2014;135(2014):329-38.

[35] Yu KW, Chan KT. Improved Energy Management of Chiller Systems by Multivariate and Data Envelopment Analyses. Appl Energ 2012;92(2012):168-74.

[36] Lee WL, Lee SH. Developing a Simplified Model for Evaluating Chiller-system Configurations. Appl Energ 2007;84(2007):290-306.

[37] Tirmizi SA, Gandhidasan P, Zubair SM. Performance Analysis of a Chilled Water System with Various Pumping Schemes. Appl Energ 2012;100(2012):238-48. 
[38] Myat A, Choon NK, Thu K, Kim YD. Experimental Investigation on the Optimal Performance of Zeolite-water Adsorption Chiller. Appl Energ 2013;102(2013):582-90.

[39] Liao Y, Huang G, Sun Y, Zhang L. Uncertainty Analysis for Chiller Sequencing Control. Energ Buildings 2014;85(2014):187-98.

[40] F.W. Yu, Chan KT. Improved Energy Performance of Air Cooled Centrifugal Chillers with Variable Chilled Water Flow. Energ Convers Manage 2008;49(6):1595-611.

[41] Chang YC, Chen WH, Lee CY, Huang CN. Simulated Annealing Based Optimal Chiller Loading for Saving Energy. Energ Convers Manage 2006;47(15-16):2044-58.

[42] Chang YC, Chen WH. Optimal Chilled Water Temperture Calculation of Mutiple Chiller Systems using Hopfield Neural Network for Saving Energy. Energ 2008;34(4):448-56.

[43] Lu YY, Chen JH, Liu TC, Chien MH. Using Cooling Load Forecast as the Optimal Operation Scheme for a Large Multi-chiller System. Int J Refrig 2011;34(8):2050-62.

[44] ASHRAE. ASHRAE Handbook HVAC Application. Atlanta: ASHRAE, Inc.; 2011.

[45] Honeywell. Engineering Manual of Automatic Control for Commercial Buildings. Minneapolis: Honeywell, Inc.; 1997.

[46] Kent A, Williams JG. Encyclopedia of Computer Science and Technology: Volume 25 - Supplement

10: Applications of Artificial Intelligence to Agriculture and Natural Resource Management to Transaction Machine. New York: Marcek Dekker, Inc.; 1991.

[47] Crawley DB, Lawrie LK, Winkelmann FC, Buhl WF, Huang YJ, Pedersend CO, et al. EnergyPlus: Creating a New-generation Building Energy Simulation Program. Energ Buildings 2001;33(4):319-31.

[48] Boyd SP, Vandenberghe L. Convex Optimization. New York: Cambridge University Press; 2004.

[49] Wetter M, Zuo W, Nouidui T, Pang X. Modelica Buildings library. J Build Perform Simu 2014;7(4):253-70.

[50] Nouidui TS, Phalak K, Zuo W, Wetter M. Validation of the Window Model of the Modelica Buildings Library. In: Proceedings of the 9th International Modelica Conference, Munich, Germany, 2012. p. 727-36.

[51] Zuo W, Wetter M, Li D, Jin M, Tian W, Chen Q. Coupled Simulation of Indoor Enviroment, HVAC and Control System by using Fast Fluid Dynamics and the Modelica Buildings Library. In: Proceedings of ASHRAE/IBPSA-USA Building Simulation Conference, Atlanta, GA, U.S.A., 2014. p. 56-63.

[52] Otter M, Årzén K-E, Dressler I. StateGraph - a Modelica Library for Hierarchical State Machines. In: Proceedings of the 4th International Modelica Conference, Hamburg, Germany, 2005. p. 569-78.

[53] Huang S, Zuo W, Sohn MD. A New Method for the Optimal Chiller Sequencing Control. In: Proceedings of the 14th Conference of IBPSA, Hyderabad, India, 2015. 
[54] Hooke R, Jeeves TA. "Direct Search" Solution of Numerical and Statistical Problems. J ACM 1961;8(2):212-29.

[55] Wetter M. GenOpt - a Generic Optimization Program. In: Proceedings of the 7th IBPSA Conference, Rio de Janeiro, Brazil, 2001. p. 601-8.

[56] National Climatic Data Center. Quality Controlled Local Climatological Data. <http://www.ncdc.noaa.gov/data-access/land-based-station-data/land-based-datasets/quality-controlled-

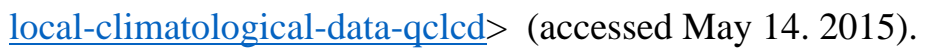

